DOI: 10.12731/2658-4034-2020-5-19-34

УДК 377

\title{
ФОРМИРОВАНИЕ ПРОФЕССИОНАЛЬНОЙ ИДЕНТИЧНОСТИ СТУДЕНТОВ 1 КУРСА КОЛЛЕДЖА
}

\section{Барышникова Е.Л.}

Цель. Статья посвящена актуальной в современном обществе теме профессиональной идентичности и средствам ее формирования в прочессе обучения профессии. В статье приведены промежуточные результаты педагогического эксперимента, проводимого в рамках исследования формирования профессиональной идентичности обучающихся в системе среднего профессионального образования посредством гендерного подхода.

Метод или методология проведения работы. Основу исследования образуют теоретические методы: изучение и анализ научно-методической литературы по исследуемой проблеме, анализ, педагогическое прогнозирование и моделирование; и эмпирические методь: наблюдение; тестирование; контент-анализ; методы математической статистики.

Результаты. Результаты работы заключаются в том, что автор наблюдает положительную динамику в исследуемых параметрах оченки сформированности профессиональной идентичности учащихся экспериментальных групп, в частности параметров «номинал профессии» и «соотношении профессии с собой». Автор делает предположение, что положительный результат был достигнут благодаря педагогическому воздействию согласно разработанной методике.

Область применения результатов. Результаты исследования могут быть применены в системе среднего профессионального образования.

Ключевые слова: профессиональная идентичность; гендерный подход; педагогические средства; результаты эксперимента. 


\section{FORMATION OF PROFESSIONAL IDENTITY OF THE FIRST YEAR STUDENTS OF A VOCATIONAL EDUCATION INSTITUTION}

\section{Baryshnikova E.L.}

Purpose. The article is devoted to the topic of professional identityand the means of its formation in the process of teaching a profession, whichboth pose a topical issue in modern society. This article presents intermediate results of a pedagogical experiment carried out within the framework of the study of formation of professional identity of students within the system of secondary vocational education using gender approach.

Methodology. The research is based on such theoretical methods as: review and analysis of scientific and methodological literature on the problem under study, analysis, pedagogical forecasting and modeling; as well as empirical methods such as: observation, testing, content analysis, and methods of mathematical statistics.

Results. The results of the work are that the author observes positive dynamics in the studied parameters of assessment of the formation of professional identity of the students in the experimental groups, particularly, in such parameters as "self-identification as a member of the profession" and "professional attribution to self". The author makes an assumption that the positive results were achieved due to beneficial pedagogical influence in accordance with the developed methodology.

Practical implications. The results of the research can be found applicable in the system of secondary vocational education.

Keywords: professional identity; gender approach; pedagogical tools; experimental results.

В настоящее время в системе российского образования понимается необходимость высвобождения личностного начала в человеке, без которого невозможна гуманизация системы общественных отношений и развитие социальной системы. Происходит переосмысление устоявшихся критериев профессионального развития, более 
глубоко изучаются вопросы профессионального самоопределения, профессионализации личности. Профессионалом можно считать человека, не только владеющего необходимыми компетенциями для достижения высокого уровня производственных показателей, но и имеющего особую систему мотиваций, устремлений, ценностных ориентаций, что, в определенной степени, составляет основу профессиональной идентичности личности.

Профессиональная идентичность - это целостное эмоциональное состояние или чувство, переживаемое как положительное отношение индивида к профессии, желание трудиться в данных условиях и по данной специальности, стремление к оптимальному выполнению профессиональной деятельности [9]. С педагогической точки зрения особый интерес представляет изучение возможностей влияния средствами обучения и воспитания на процесс формирования профессиональной идентичности старшеклассников и студентов. Поэтому в нашем исследовании мы рассматриваем проблему формирования профессиональной идентичности в процессе профессионального обучения.

Безусловно, профессиональная идентичность студента и специалиста - это два разных феномена. На этапе профессионального обучения закладываются лишь предпосылки профессиональной идентичности, а ее формирование и дальнейшее развитие происходят после первичной адаптации молодого специалиста, в периоды более плотной профессиональной активности [11]. Однако как отечественные исследователи (А.А. Азбель [1], Т.В. Мищенко [8], Л.Б. Шнейдер [14], Ю.В. Гарбузова [3], В.А. Кениг [6], У.С. Родыгина [12]), так и зарубежные [16,19], подчеркивают важность периода профессионального обучения и подготовки в становлении профессиональной идентичности. Ведь именно для юношеского возраста характерно интенсивное самоопределение, как в личной сфере, так и в профессиональной. Практически все юноши и девушки думают о выборе профессии и начинают учёбу по выбранной специальности [4]. Однако многие молодые люди неясно представляют себе свою будущую профессиональную деятельность и сомневаются в правиль- 
ности своего выбора на протяжении всего обучения. Это происходит, потому что проектирование и становление личности будущего профессионала в процессе обучения пока не входит в задачи учебных заведений. В нашем исследовании мы полагаем, что начинать «погружать» студентов в профессию необходимо уже с первого курса, еще до столкновения с трудностями общепрофессиональных и специальных дисциплин, чтобы заранее создать у них положительную учебную мотивацию и укрепить уверенность в собственных силах. Очевидно, что основную роль в формировании профессиональной идентичности студентов играет образовательная среда. Основными средствами педагогического воздействия на первом курсе являются насыщение информацией из области профессиональных знаний содержания общеобразовательных дисциплин и организация внеурочной деятельности студентов на профессиональную тематику (внеклассные мероприятия и классные часы, факультативные занятия, участие в конкурсах, проектная деятельность и др.).

Профессиональная идентичность личности является результатом воздействия многих взаимосвязанных внешних и внутренних факторов, в систему которых входит и гендер. Исследования в области гендерной педагогики показывают, что успешность обучения молодых людей студенческого возраста во многом определяется характером проявления психофизиологических особенностей юношей и девушек. Юноши и девушки отличаются по уровню активации эмоций в процессе обучения, познавательным способностям и познавательным интересам, восприятию окружающего мира, темпу, стратегии переработки и усвоения информации, темпу подачи новой информации, организации внимания, продолжительности периода врабатываемости, уровню адаптивных возможностей организма и психики, уровню природной агрессивности, отношению положительной и отрицательной оценки своей работы и др. [13]. Исследования психофизиологических различий полов подробно рассмотрены в работах отечественных [5] и иностранных ученых $[15,17,18]$. Профессиональное развитие девушек и юношей также имеет различия, проявляющиеся на физическом, физиологическом, психологическом, социальном уровнях развития 
личности [7]. Поэтому для эффективного влияния на процесс формирования профессиональной идентичности, преподавателю необходимо учитывать возрастные и гендерные особенности студентов, а также специфику профессии, осваиваемой студентами, на уровне содержания и методики преподавания.

Таким образом, цель нашего исследования заключается в разработке и обосновании педагогических средств формирования профессиональной идентичности у студентов средних учебных заведений в рамках гендерного подхода.

Для достижения поставленной цели был организован педагогический эксперимент на базе ГАПОУ СО «Автомобильно-дорожный колледж», в группах студентов 1-го курса, обучающихся по направлениям «Техническое обслуживание и ремонт автомобильного транспорта» (далее АMO) и «Организация перевозок и управление на автомобильном транспорте», (далее ОПУ).

Эксперимент проходил в несколько этапов. Первый этап - диагностический. В начале учебного года были выбраны три группы студентов 1 курса: две экспериментальных и одна контрольная. Первая экспериментальная группа - АМО, юноши, вторая - ОПУ, юноши и девушки. Контрольная группа - AMO, юноши. Все группы обучаются на бюджетной основе. В этих группах была проведена стартовая диагностика с помощью комплекса психодиагностических методик и контент-анализа эссе на тему «Моя будущая профессия». В качестве компонентов профессиональной идентичности, контролируемых в ходе эксперимента, были выбраны: профессиональный «образ Я», удовлетворенность выбранной профессией, статус профессиональной идентичности. В соответствии с этими компонентами были использованы следующие методики исследования: «Кто Я?» М. Кун и Т. Макпартлэнд для оценки профессионального «образа Я», «15 признаков принимаемой профессии» Т.В. Мищенко для оценки удовлетворенности выбранной профессией и методика изучения профессиональной идентичности Л.Б. Шнейдер для определения статуса профессиональной идентичности. Результаты стартовой диагностики отражены в нашей статье [2]. 
Второй, основной этап продолжался в течение учебного года и представлял собой работу с экспериментальными группами по разработанной методике, суть которой заключается в создании профессионально-ориентированной образовательной среды и воздействии на точки соприкосновения между профессионально-важными качествами будущих специалистов и психофизиологическими особенностями юношей и девушек в процессе обучения. В конце учебного года была проведена контрольная диагностика, которая показала определенные изменения в показателях методик.

1. Методика «Кто я?» представляет собой нестандартизированное самоописание с открытой формой. Испытуемому предлагается 10 раз письменно ответить на вопрос «Кто Я». Ответ на данный вопрос освещает все сферы представлений человека о своей личности и ее ядре «Я», демонстрирует область разделения «реального» и «идеального» в самосознании испытуемого. Методика применялась при исследовании профессиональной идентичности в исследовании Регуш Н.Л. [10], В нашей модификации студентам предлагалось 10 раз ответить на вопрос «Кто я в профессии?». Таким образом, с помощью данной методики исследовались профессиональные «Я-образы» студентов. Очевидно, что ответы обучающихся скорее отражают их идеалистические представления о профессии, поскольку большинство из них имеют слабое представление о содержании труда и не имеют личного статуса в профессиональной деятельности. Поэтому мы сделали основной акцент на параметре «номинал профессии» при оценивании результатов диагностики. В нашем исследовании мы полагаем, что определение себя как носителя профессии (автомеханик, диспетчер и пр.), уже содержит зачатки идентификации себя с будущей профессией. Также оценивались параметры «предмет труда», «содержание труда» - по которым можно оценить осведомленность студентов о характере будущей профессиональной деятельности, и «отношение к труду». В течение учебного года студенты активно знакомились с профессией и имели возможность лучше узнать ее содержание и особенности, понять свое отношение и желание продолжать обучение. Сравним результаты стартовой и контрольной диагностик. 

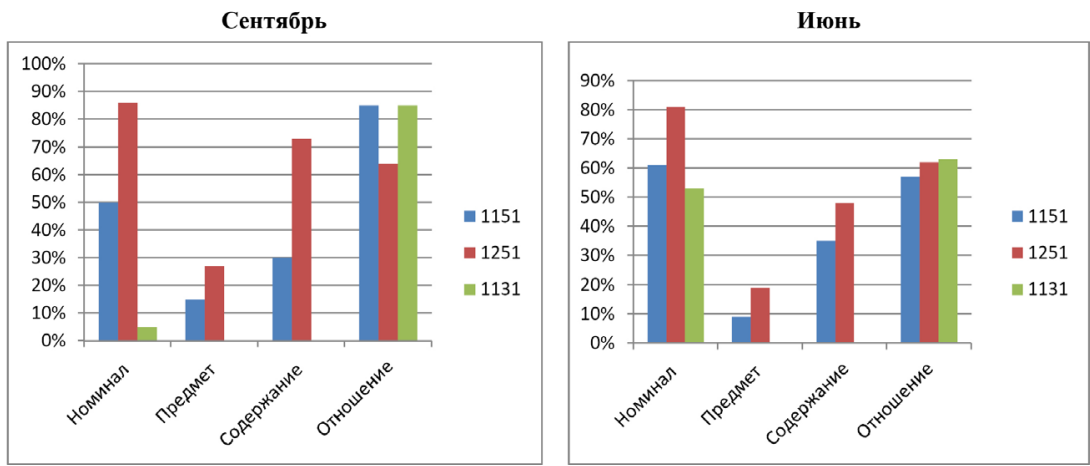

1151 - экспериментальная, юноши;

1251 - контрольная, юноши;

1131 - экспериментальная, смешанная.

В обеих экспериментальных группах наблюдается положительная динамика в показателе «номинал профессии». Это значит, что большее число студентов при описании себя стали называть профессию и, следовательно, ассоциировать себя с ней. С точки зрения статистики, значимые изменения произошли в смешанной экспериментальной группе. Расчет критерия Уилкоксона показал высокую значимость изменения по этому параметру $(0,005)$. Это подтверждает также расчет критерия углового преобразования Фишера $(\mathrm{p}<0,01)$. У контрольной группы выраженной динамики по этому показателю нет. Это свидетельствует в пользу нашего предположения, что подобранные нами педагогические средства могут положительно влиять на восприятие студентами профессии и повышать у них уверенность в своем выборе.

2. Методика исследования профессиональной идентичности Л.Б. Шнейдер построена на принципах прямого и цепного ассоциативного теста. Испытуемым предъявлялись ключевые ассоциации со словами-стимулами профессионал/не профессионал и предлагалось подчеркнуть среди слов ассоциативного ряда те слова, которые имеют отношение к нему и его профессиональной жизни. По полученному результату, согласно ключу, выделялось пять уровней профессиональной идентичности: преждевременная, диффузная, мораторий, достигнутая или псевдопозитивная идентичность. 

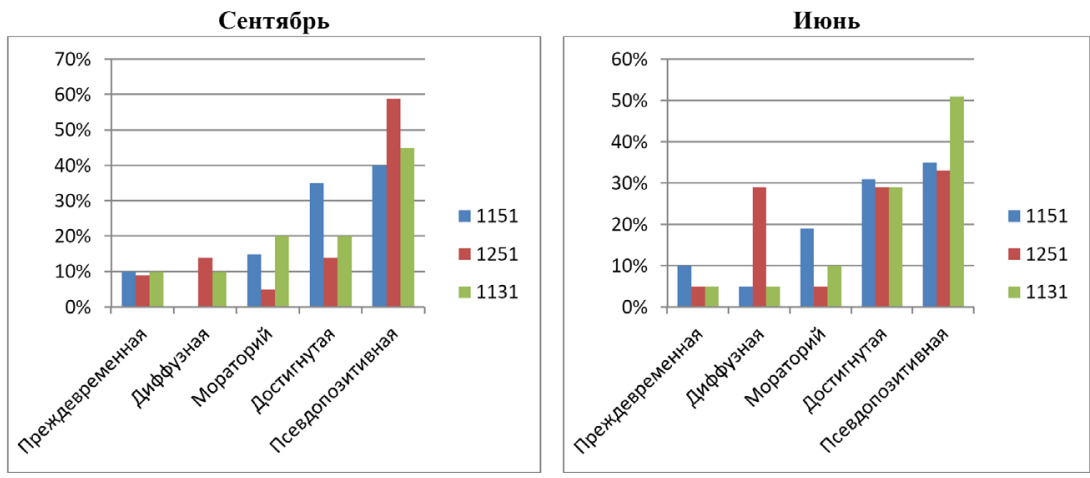

По результатам диагностики у смешанной экспериментальной группы наблюдается небольшая положительная динамика по показателю «достигнутая профессиональная идентичность». Это можно объяснить тем, что в процессе обучения студенты этой группы больше узнали о выбранной профессии и стали больше ассоциировать себя с ней. В экспериментальной группе юношей наоборот, произошло снижение этого показателя при росте остальных. Возможно, некоторые студенты в течение учебного года, погружаясь в профессиональную среду, переосмыслили свой выбор и задумались о его правильности. Наиболее адекватная картина наблюдается в контрольной группе, где произошло снижение «псевдопозитивной идентичности» с одновременным ростом «достигнутой» и «диффузной». Это показывает, что в процесс обучения одна часть студентов укрепилась в своем первоначальном выборе, а другая часть наоборот, стала сомневаться. Необходимо отметить, что обработка данных статистическими методами не выявила значимых изменений по параметрам этой диагностики у испытуемых.

3. Методика «15 признаков профессии» Т.В. Мищенко направлена на исследование отношения человека к содержанию, условиям профессиональной деятельности и профессионализации в целом (удовлетворенность человека трудом). В нашей модификации мы предложили студентам назвать по три желаемых признака профессии в пяти категориях: сфера деятельности, профессиональные обязанности, условия труда, руководство, карьерный рост и пер- 
спектива. Затем студенты подчеркивали те признаки, которые, как они считают, будут присутствовать в выбранной профессии. Коэффициент удовлетворенности профессией равен отношению количества качеств, имеющихся в профессии к количеству качеств, желаемых в профессии.

Процент удовлетворенности профессией к концу учебного года

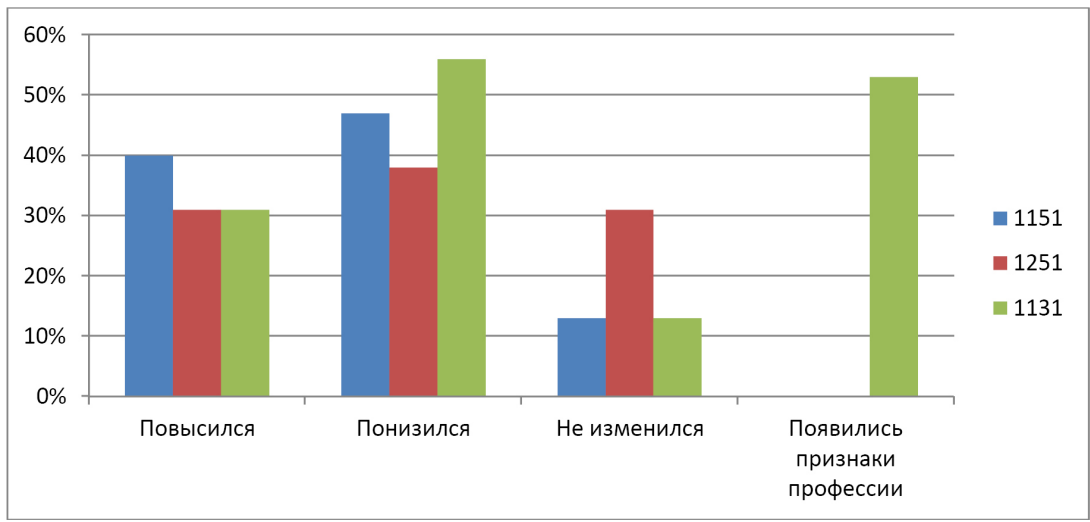

Согласно полученным результатам по диагностике удовлетворенности выбором профессии, в целом во всех группах процент удовлетворенности профессией к концу учебного года стал ниже. Это можно объяснить тем, что за время обучения студенты больше узнали о выбранной профессии и их первоначальное излишне оптимистичное представление о ней сменились более реалистичным отношением. С точки зрения статистики, эти изменения не являются значимыми. Стоит отметить значительные изменения, произошедшие в смешанной экспериментальной группе. В начале года, студенты, описывая желаемые признаки профессии, практически не называли признаки той, на которую пришли учиться. Тогда как в конце года, большее число студентов уже указывали признаки именно выбранной профессии. Расчет критерия углового преобразования Фишера показал высокую значимость этих изменений $(\mathrm{p}<0,01)$ что свидетельствует о положительной динамике, произошедшей в течение учебного года. 
4. По результатам диагностики таких параметров, как: соотнесение профессии с собой, качественная оценка профессии и др., проводимой методом написания Эссе на тему «Я и моя профессия» были получены следующие результаты.
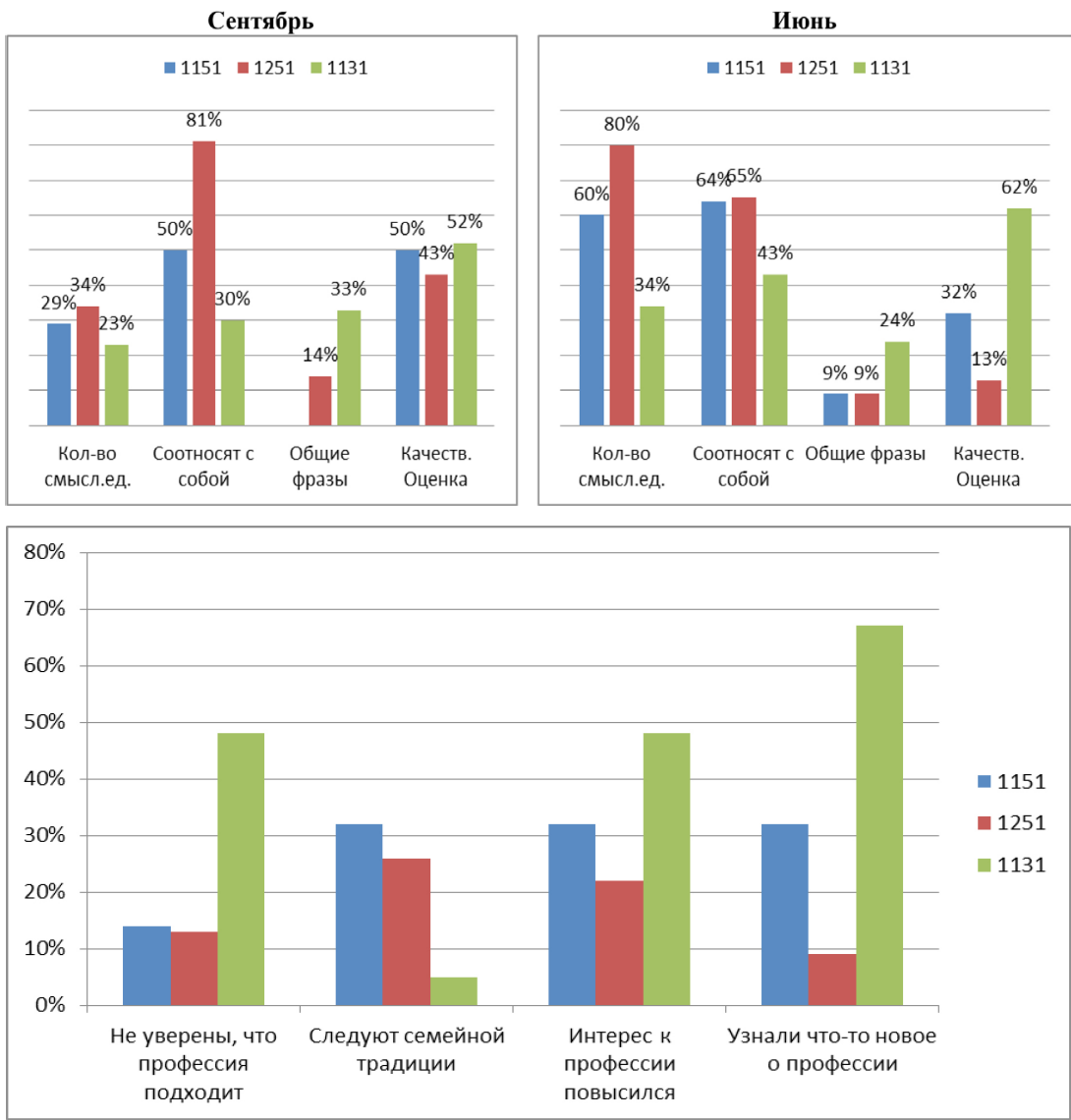

Контент-анализ эссе показал положительную динамику в обеих экспериментальных группах по показателю «соотношение профессии с собой». Расчеты критериев Уилкоксона $(0,008)$ и Фишера $(\mathrm{p}<0,01)$ показали высокую значимость изменений по этому параметру в юношеской экспериментальной группе. Также выраженные изменения произошли по параметру «количество смысловых единиц» в обеих юношеских 
группах. Критерий Уилкоксона $(0,001)$ и Фишера $(\mathrm{p}<0,01)$. Стоит обратить внимание, что в юношеских группах в целом уровень понимания и принятия выбранной профессии был значительно выше, чем в смешанной, что связанно в первую очередь со спецификой профессии. Профессия «автомеханик» имеет вещественный, осязаемый предмет и результат труда - транспортные средства, механизмы, оборудование и т.д. Поэтому даже студенты-первокурсники, не имеющие опыта работы по профессии, неплохо представляют себе ее основные составляющие. Тогда как специальность «организация перевозок» предполагает оперирование схемами, мысленными образами.Поэтому студенты, еще не знакомые с особенностями данной профессии, не могут в полной мере представить себе ее суть и понять, подходит ли им эта деятельность. Это подтверждается отзывами студентов после посещения ими в рамках эксперимента экскурсии на возможное место будущей работы - студенты АМО посещали станцию техобслуживания автомобилей и автосервис, а студенты ОПУ - диспетчерскую службу ЕМУП МОАП. Будущие автомеханики об экскурсии отозвались положительно, однако многие отметили, что ничего нового не узнали. Тогда как в группе ОПУ экскурсия серьезно расширила их представления о профессии и многие сказали, что даже не представляли, что именно так может выглядеть их будущая работа. Несмотря на то, что некоторые испытали разочарование, примерно половина студентов в своих эссе указали, что уверенность в том, что такая профессия им подходит, у них повысилась. Также студенты смешанной группы в большей мере, чем студенты-юноши, отметили в эссе положительное воздействие профориентационных игр по методике Н.С. Пряжникова.

Также мы попросили преподавателей дать общую оценку группам. По совокупности впечатлений получились такие характеристики. 1) Экспериментальная группа юноши: спокойные, взрослые, серьезные, но при этом неактивные, ленивые, хулиганистые. Группа не очень сплоченная, ребята склонны перекладывать ответственность друг на друга. Нет выраженного лидера, есть несколько более активных ребят, на которых ориентируются остальные. 2) Контрольная группа юноши: творческие, интересующиеся, мотивированные, но при этом шумные, 
не собранные, «как дети». Нет выраженного лидера, но в целом группа довольно сплоченная. 3) Экспериментальная смешанная: старательные, но слабые, неактивные, незаинтересованные. Девушки общаются в мини-группах, лидера нет. Юноши держатся от них отдельно, лидерские роли на себя также не берут. Девушки им «не дают рот открыть».

\section{Заключение}

На начальном этапе исследования экспериментальная и контрольная группы AMO были во многом похожи, но контрольная группа была по большинству наблюдаемых параметров сильнее. В течение учебного года в обеих группах произошел ряд изменений в исследуемых параметрах, одни росли, другие снижались, но только в экспериментальной группе произошел рост таких важных параметров как «номинал профессии» и «соотношении профессии с собой». Это позволяет сделать вывод, что в целом воздействие подобранных организационно-педагогических условий учебного процесса благоприятно сказалось на формировании профессиональной идентичности юношей этой группы. Смешанная экспериментальная группа ОПУ была в начале учебного года на значительно более слабом уровне по сравнению с юношескими группами. Но именно в ней произошел наибольший рост исследуемых параметров: «номинал профессии», «соотношение профессии с собой» и «признаки профессии», что явно указывает на более осмысленное отношение к выбранной профессии по сравнению с тем, что было в начале обучения. По наблюдениям, в этой группе основное воздействие оказала совокупность факторов: накопление информации о сути и особенностях профессии на уроках и внеклассных мероприятиях и внутренняя проработка этой информации на профориентационных играх. На ребят группы AMO предположительно больше имели воздействие общий фон профессионально-ориентированной среды и общение друг с другом на профессиональные темы. На начальном этапе разница в результатах групп АМО и ОПУ скорее была связана с выбором профессии, нежели с гендерным составом групп. Тогда как разница в результатах юношеской и смешанной экспериментальных групп, может свиде- 
тельствовать, что процесс формирования профессиональной идентичности протекает неодинаково у юношей и девушек.

Информация о конфликте интересов. Авторы заявляют об отсутствии конфликта интересов.

Информация о спонсорстве. Исследование выполнено без участия спонсоров.

\section{Список литературы}

1. Азбель А.А. Способы диагностики статусов профессиональной идентичности у студентов // Материалы научно-практической конференции «Психологическая подготовка педагога в России: история и современность» / Под. ред. Л.А. Регуш. СПб., 2005. С. 25-34.

2. Барышникова Е.Л. Формирование профессиональной идентичности в условиях гендерного подхода в педагогике [Эл. ресурс] // Современные исследования социальных проблем, 2017, Т. 8, № 12-2. С. 38-49.

3. Гарбузова Г.В. Процесс формирования профессиональной идентичности студентов // Известия Российского государственного педагогического университета им. А.И. Герцена. 2007. Т.18, № 44. С. 340-344. https://lib.herzen.spb.ru/media/magazines/contents/1/18(44)/ garbuzova_18_44_340_344.pdf

4. Донцов Д.А., Донцова М.В. Возрастные особенности юношеского (студенческого) возраста [Электронный ресурс] // Образовательные технологии, 2013. №2 C. 34-42. URL: https://iedtech.ru/files/ journal/2013/2/dontsovs.pdf (дата обращения 04.05.2018).

5. Каменская Е.Н. Гендерный подход в педагогике: дис...доктора пед. наук. Ростов-на-Дону, 2006. 385 с.

6. Кениг В.А. Становление профессиональной идентичности у работающих студентов: автореф. дис. ... канд. психол. наук. М., 2008. 21 с.

7. Клецина И.С. Теоретические проблемы гендерной психологии // Мир психологии. 2001. № 4. С. 154-166.

8. Мищенко Т. В. Становление профессиональной идентичности у студентов педагогического вуза: Дис. ... канд. психол. наук: 19.00.07 Ярославль, 2005. 224 с. 
9. Поварёнков Ю.П. Психологическая характеристика профессиональной идентичности субъекта труда [Электронный ресурс] // Вестник Костромского государственного университета. Серия: Педагогика. Психология. Социокинетика. 2014. №3. URL: https://cyberleninka.ru/article/n/psihologicheskaya-harakteristikaprofessionalnoy-identichnosti-subekta-truda (дата обращения: 04.05.2018).

10. Регуш Н.Л. Профессиональная идентичность учителя на разных этапах педагогической деятельности: дисс....канд. психол.наук: 19.00.07. Санкт-Петербург, 2002. 167 с.

11. Реньш М.А., Лесик А.В. Профессиональный стаж как фактор становления профессиональной идентичности [Электронный ресурс] // Психологические исследования: электрон. науч. журн. 2011. №3(17). URL: http://psystudy.ru/index.php/num/2011n3-17/487-rensh-lesik17. html (дата обращения: 04.05.2018).

12. Родыгина У.С. Психологические особенности профессиональной идентичности студентов // Психол. наука и образование. 2007. Т. 12, №4. С. 39-51.

13. Симонов В.М., Коробкова С.А. Основы психодидактики как фактора технологизации обучения студентов на основе гендерного подхода // Известия ВолгГТУ. 2007. Т. 4, №7. С. 58-60.

14. Шнейдер Л. Б. Профессиональная идентичность: Монография. М.: MOCУ, 2001. $272 \mathrm{c}$.

15. Eagly A. H., Johnson B. T. Gender and leadership style: a meta-analysis // Psychological bulletin. 1990, Vol. 108, No. 2, pp. 233-256.

16. Erikson E. H. Identity: Youth and crisis. New York: W. W. Norton Company, 1968. 336 p.

17. Feingold A. Gender differences in personality: a meta-analysis // Psychological bulletin. 1994. 116(3), pp. 429-456. https://doi. org/10.1037/0033-2909.116.3.429

18. Maccoby E. E. The two sexes: growing up apart, coming together. Harvard University Press, 1999. 376 p.

19. Marcia J. E. Identity in adolescence // Adelson J. (ed.). Handbook of adolescent psychology. N.Y.: John Wiley, 1980, pp. 159-187. 


\section{References}

1. Azbel A.A. Materialy nauchno-prakticheskoy konferentsii «Psikhologicheskaya podgotovka pedagoga v Rossii: istoriya i sovremennost'» [Materials of the scientific-practical conference "Psychological training of a teacher in Russia: history and modernity"] / ed. L.A. Regush. SPb., 2005. S. 25-34.

2. Baryshnikova E.L. Sovremennye issledovaniya sotsial'nykh problem [Modern Studies of Social Issues], 2017, V. 8, No. 12-2. P. 38-49.

3. Garbuzova G.V. Izvestia of the Russian State Pedagogical University named after A.I. Herzen. 2007. Vol. 18, No. 44. P. 340-344. https://lib.herzen.spb.

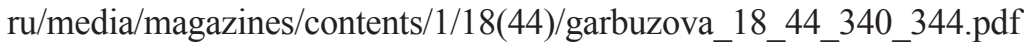

4. Dontsov D.A., Dontsova M.V. Obrazovatel'nye tekhnologii [Educational technologies], 2013. No. 2 pp. 34-42. URL: https://iedtech.ru/files/journal/2013/2/dontsovs.pdf (accessed 05/04/2018)

5. Kamenskaya E.N. Gendernyy podkhod v pedagogike [Gender approach in pedagogy]. Rostov-on-Don, 2006.385 p.

6. Kenig V.A. Stanovlenie professional'noy identichnosti u rabotayushchikh studentov [Formation of professional identity among working students]. M., 2008. 21 p.

7. Kletsina I.S. Mir psikhologii [World of psychology]. 2001. No. 4. P. 154-166.

8. Mishchenko T. V. Stanovlenie professional'noy identichnosti u studentov pedagogicheskogo vuza [Formation of professional identity among students of a pedagogical university].Yaroslavl, 2005. 224 p.

9. Povarenkov Yu.P. Vestnik Kostromskogo gosudarstvennogo universiteta. Seriya: Pedagogika. Psikhologiya. Sotsiokinetika [Bulletin of the Kostroma State University. Series: Pedagogy. Psychology. Sociokinetics]. 2014. No. 3. URL: https://cyberleninka.ru/article/n/psihologicheskaya-harakteristika-professionalnoy-identichnosti-subekta-truda (accessed 05/04/2018).

10. Regush N.L. Professional'naya identichnost'uchitelya na raznykh etapa$k h$ pedagogicheskoy deyatel'nosti [Professional identity of a teacher at different stages of pedagogical activity]. St. Petersburg, 2002. 167 p.

11. Rensh M.A., Lesik A.V. Psikhologicheskie issledovaniya [Psychological research]. 2011. No. 3 (17). URL: http://psystudy.ru/index.php/ num/2011n3-17/487-rensh-lesik17.html (accessed 05/04/2018). 
12. Rodygina U.S. Psikhologicheskaya nauka i obrazovanie. 2007. V. 12, No. 4. P. 39-51.

13. Simonov V.M., Korobkova S.A. Izvestia VolgSTU. 2007. T. 4, No. 7. P. $58-60$.

14. Schneider L.B. Professional identity: Monograph. Moscow: MOSU, 2001. 272 p.

15. Eagly A.H., Johnson V.T. Gender and leadership style: a meta-analysis. Psychological bulletin. 1990, Vol. 108, No. 2, pp. 233-256.

16. Erikson E. H. Identity: Youth and crisis. New York: W. W. Norton Company, $1968.336 \mathrm{p}$.

17. Feingold A. Gender differences in personality: a meta-analysis. Psychological bulletin. 1994. 116 (3), pp. 429-456. https://doi.org/10.1037/00332909.116.3.429

18. Maccoby E.E. The two sexes: growing up apart, coming together. Harvard University Press, 1999.376 p.

19. Marcia J.E. Identity in adolescence. Adelson J. (ed.). Handbook of adolescent psychology. N.Y.: John Wiley, 1980, pp. 159-187.

\section{ДАННЫЕ ОБ АВТОРЕ}

Барышникова Екатерина Леонидовна, соискатель ученой степени кандидата педагогических наук ФГБОУ ВО Уральский государственный педагогический университет

пр. Космонавтов, 26, г. Екатеринбург, Свердловская область, 620012, Российская Федерачия baryshnikova-ecat@yandex.ru

\section{DATA ABOUT THE AUTHOR}

Baryshnikova Ekaterina Leonidovna, $\mathrm{PhD}$ applicant

Ural State Pedagogical University

26, Kosmonavtov pr., Yekaterinburg, Sverdlovsk region, 620017 Russian Federation

baryshnikova-ecat@yandex.ru

ORCID: 0000-0002-5541-9613 